تأثير دَر آسيبى عصاره درمنه (Artemisia sieberi) بر خصوصيات سبزشدن و جذب عناصر

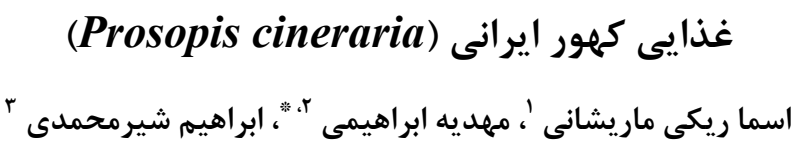

جكيده مبسوط

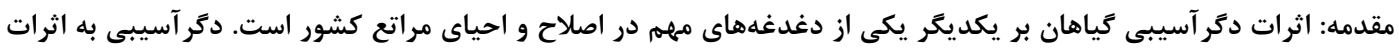

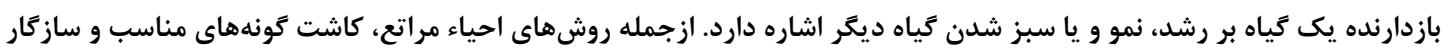

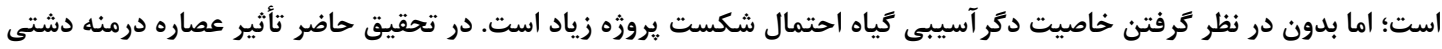

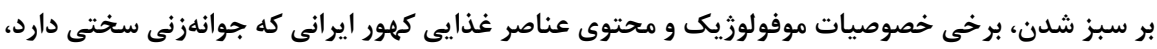

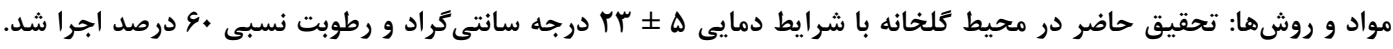

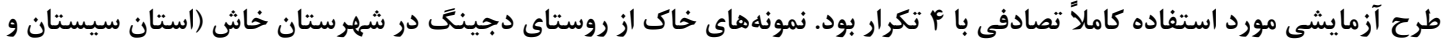

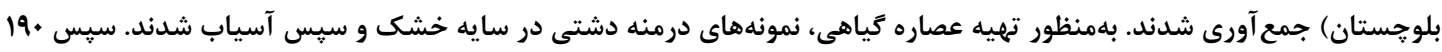

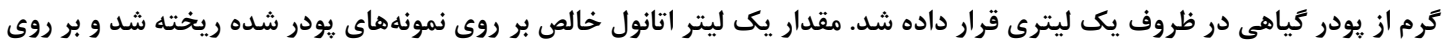

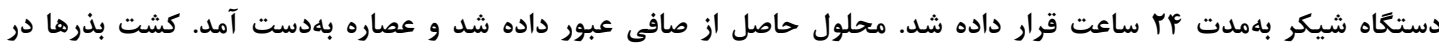

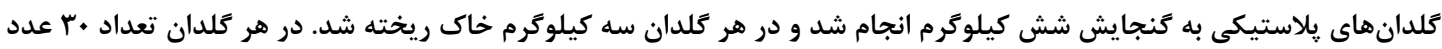

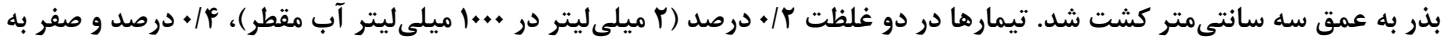

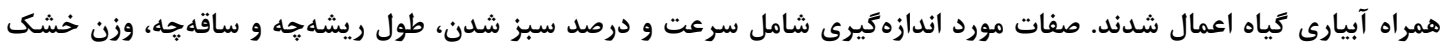

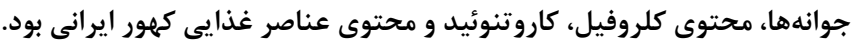

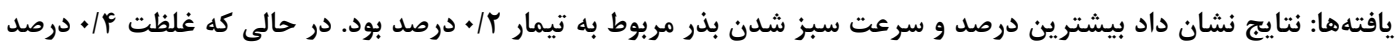

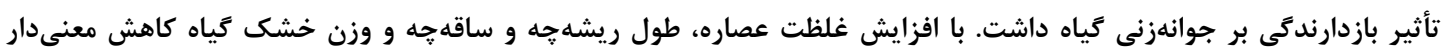

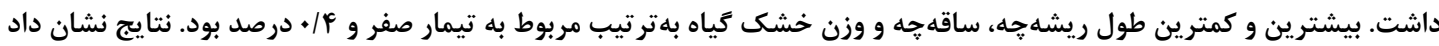

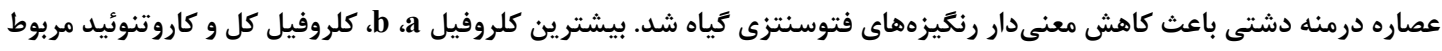

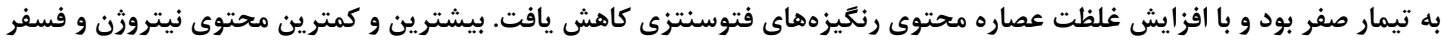

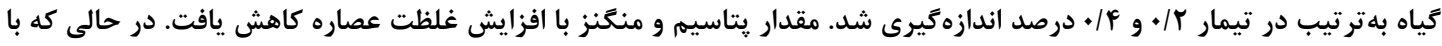

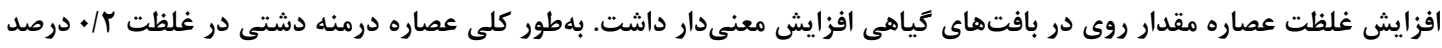
باعث افزايش سبز شدن كهور ايرانى شد.

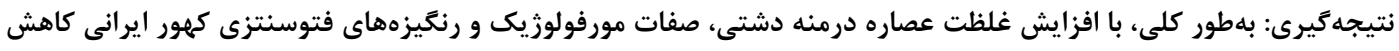

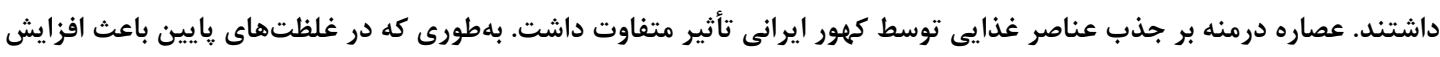

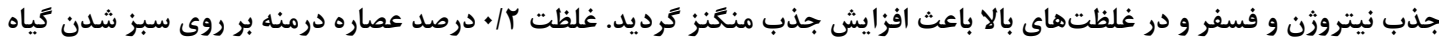

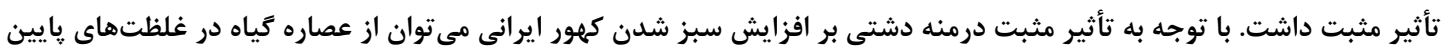

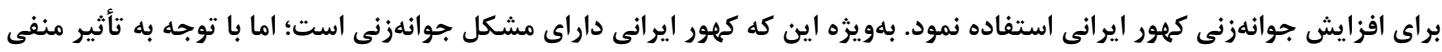

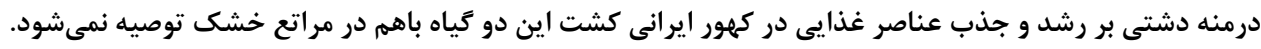
وازمهاى كليدى: درصد سبز شدن، دتر آسيبى، رنكَيزههاى فتوسنتزى، منكَنز

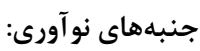
1 - عصاره درمنه دشتى تأثير بازدارنده بر سبز شدن بذر كهور بهور ايرانى داشت.

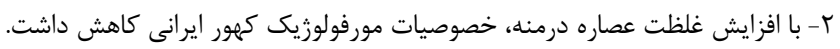

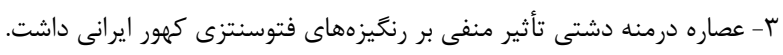

DOI: $10.29252 /$ yujs.5.1.21

CrossMark
' دانش آموخته كارشناسى ارشد مرتعدارى، كروه مرتع و آبخيزدارى، دانشعاه زابل

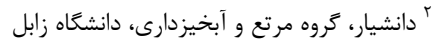

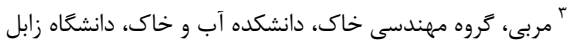

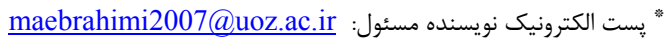

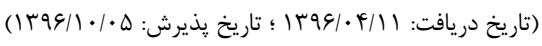


كونههاى مناسب و ساز كار است؛ اما بايد در نظر داشت،

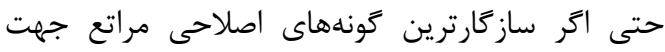

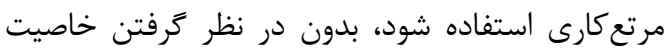

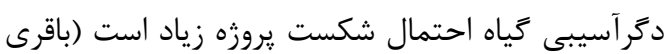

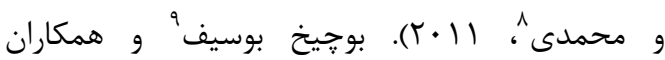

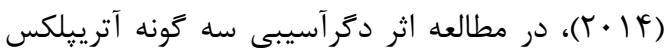
Atriplex nummulariat, A. canescens, A. ) Chenopodium بر جوانهزنى و رشد اوليه (halimus تأق album

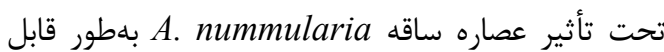
ملاحظهاى كاهش يافت. كازرونى منفرد" و همكاران

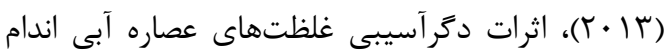
هوايى شبدر برسيم بر جوانهزنى و رشد ريشهات Aاى هرز Amaranthus albus (تاجخروس سفيد)، Solanum nigrum (تاجخروس هيبريد) hybridus (تاجريزى سياه) و سلمه تره را مورد ارزيابى قرار دادند.

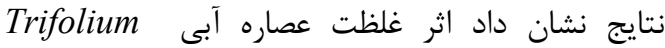
alexandrium

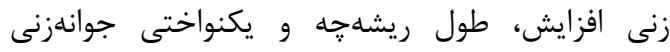
معنى دار بود و در مجموع، كونه تاجريزى سياه مقاوم-

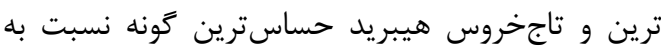
حضور عصاره آبى شبدر برسيم بودند.

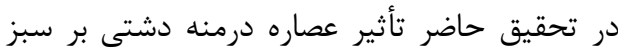
شدن، برخى خصوصيات موفولوزيك و محتوى عناصر

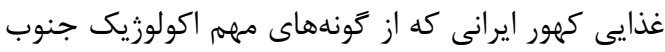
ايران است و جوانهزنى سختى دارد، مورد مطالعه قرار

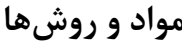

آماده كردن خاك، كشت كلدانى و تهيه عصاره كَياهى تحقيق حاضر در قالب طرح كاملاً تصادفى با ب تكرار در محيط كلخانه (شرايط دمايى ه

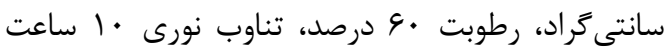
روشنايى fl ساعت تاريكى) در شهرستان خاش اجرا

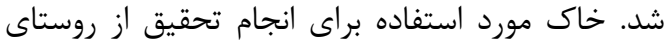

\footnotetext{
${ }^{8}$ Bagheri and Mohammadi

${ }^{9}$ Bouchikh-Boucif

${ }^{10}$ Kazerooni Monfared
}

مراتع ايران يكى از مهمترين و با ارزشترين منابع ملى كشور است كه بهرهبردارى صحيح توأم با عمليات اصلاح و احياء آنها مىتواند نقش اساسى در جهت

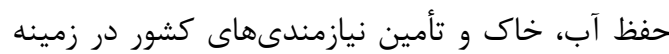

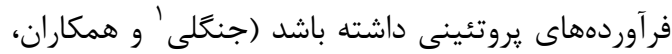

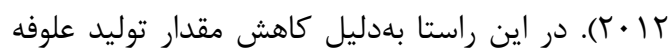
مراتع در اثر عوامل طبيعى و انسانى، افزايش توليد علوفه

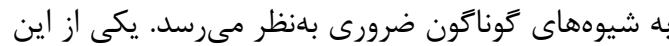

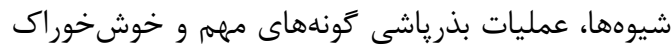
در مراتع است كه در صورت موفق بودن مىتواند باعث

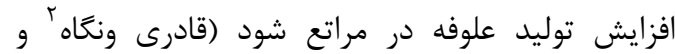

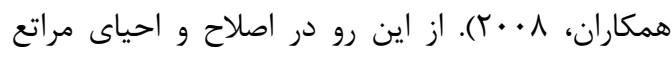
قبل از كشت بايد خصوصيات فيزيكى و مورفولوزيكى كياه كشت شده با كياه بومى منطقه لحاظ كردد.

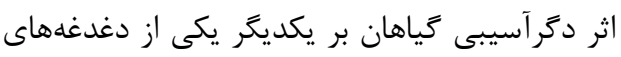

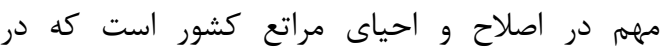

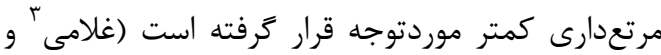

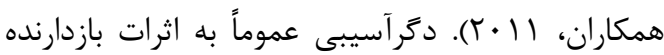
يك كياه بر رشد، نمو و يا جوانهزنى كياه ديكر اشاره

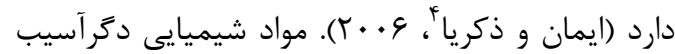

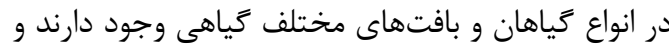
اين تركيبات فرآوردههاى ثانويه يا توليدات اضافى حاصل

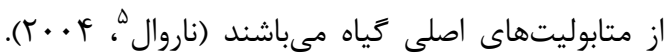
اين تركيبات جزء مواد ثانويه كياهى يا مواد فرعى دئي

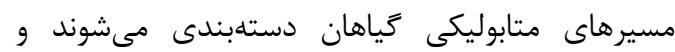

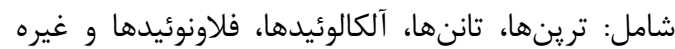

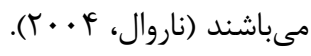

با توجه به اينكه منابع طبيعى بستر حيات دستكاههاى اكولوزيك مىباشد، شناخت عوامل تأثير كذار

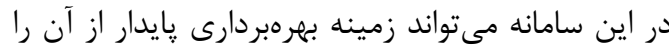

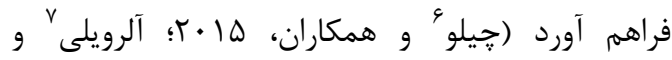
همكاران، ها •r). ازجمله روشها احياء مراتع، كاشت

\footnotetext{
${ }^{1}$ Jangali

${ }^{2}$ Ghaderi Vangah

${ }^{3}$ Gholami

${ }^{4}$ Iman and Zakaria

${ }^{5}$ Narwal

${ }^{6}$ Chillo

${ }^{7}$ Al-Rowaily
} 
براى محاسبه سرعت و درصد سبز شدن، گياهان كشت شده بdمدت f| بذرهاى سبز شده يادداشت شد. سيس درصد و سرعت بـ

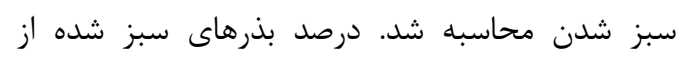
رابطهى ( محاسبه شد (باجى ' و همكاران، Y + . ب). $\mathrm{EP}=(\mathrm{Ni} / \mathrm{S}) \times 100$

رابطه ) i درصد سبز شدن، Ni EP تعداد بذر سبز شده تا روز ام و S هم تعداد كل بذر كشت شده مىباشد. سرعت

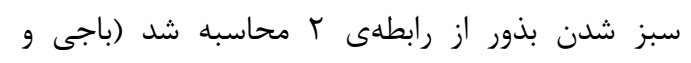

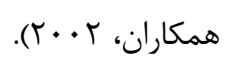
رابطه r سرعت سبز شدن (برحسب تعداد بذر سبز شده در

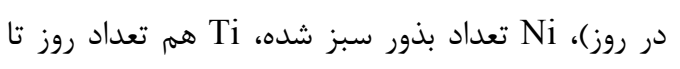

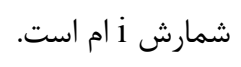

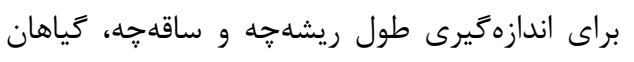
كشتشده يس از رسيدن بهحد نصاب (fأ روز) برداشت شدند. يس از شستشوى ريشه گياه با آب مقطر، ريشه-

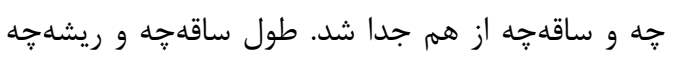

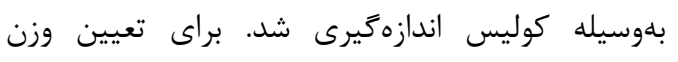

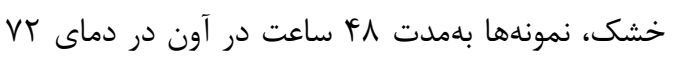

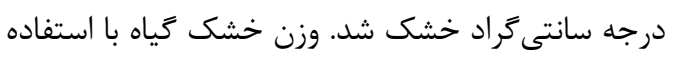

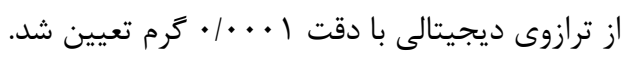

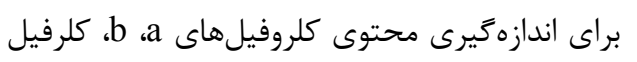

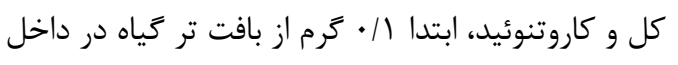
هاون تينى با ه ميلىليتر استون • م درصد ساييده شد.

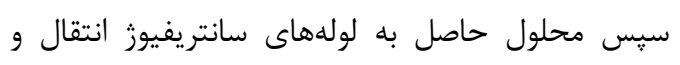
بقاياى موجود در هاون، دو مرتبه با ه ميلىليتر استون

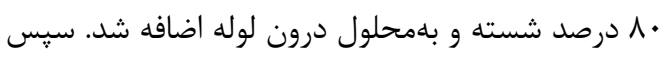

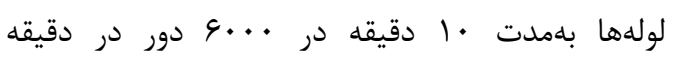
سانتريفيوز (مدل دستخاه:Sigma, 14-1, Germany)

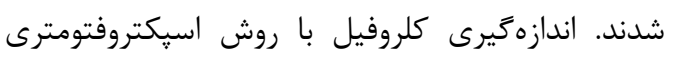

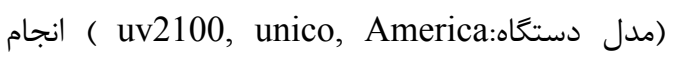
گرفت. به اين ترتيب كه مقدار جذب محلولها در طول

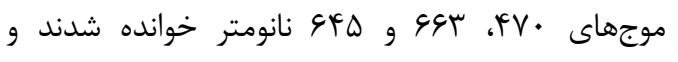
محتوى كلروفيل b, a و كاروتنوئيد از روابط سا، أ و ه و

\footnotetext{
${ }^{1}$ Bajji

2 Emergence percentage

${ }^{3}$ Emergence rate
}

دجينت در له كيلومترى شهرستان خاش جمعآورى شد. خاك طبيعى بدون استفاده از هيج نوع كودى دئن

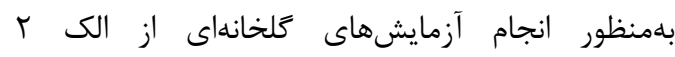

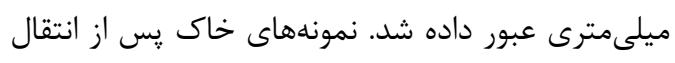

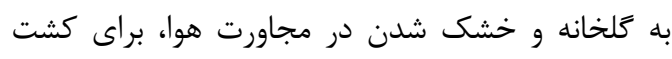

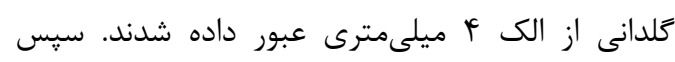
برخى خصوصيات فيزيكى و شيميايى خاك شامل: بافت خاك (لومى شنى) به روش رئ هيدرومترى، اسيديته،

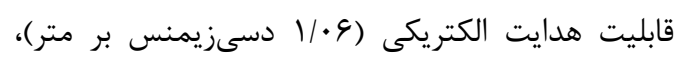

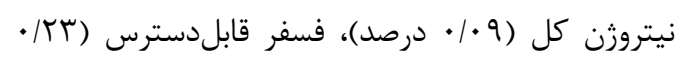

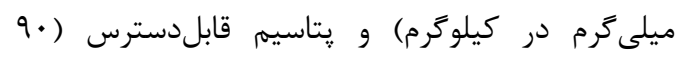
ميلى گرم در كيلوگرم) اندازهزيرى شد.

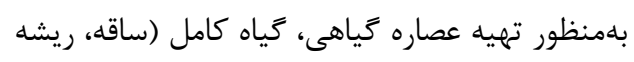
و برگ) درمنه دشتى از مراتع تيغ آب شهرستان

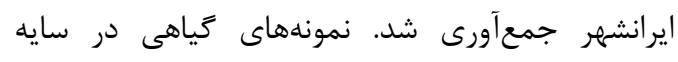

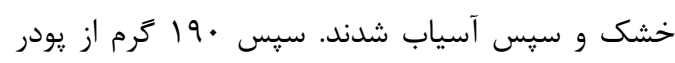

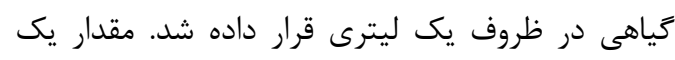
ليتر اتانول خالص روى نمونههاى يودر شده ريخته شد و ورى

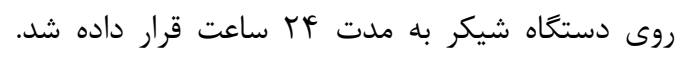

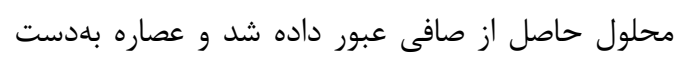
آمد. بهمنظور كشت بذرها، از كلدانهاى يلاستيكى بـ كنجايش شش كيلوگرم استفاده و در هر خلدان سه كيلوكرم خاى ريخته شد. رطوبت خاى كلدانها درصد ظرفيت زراعى نحه داشته شد. قبل از كشت، ابتدا

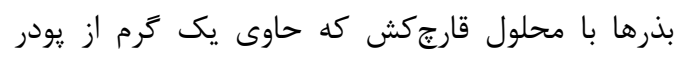

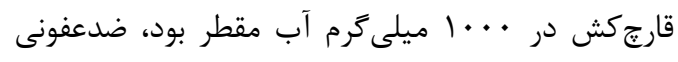
كرديدند. بهدليل ريشه عميق كهور ايرانى و جوانهزنى

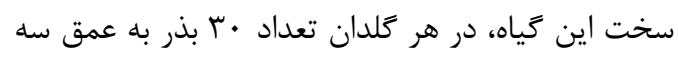
سانتىمتر كشت شد. در اين يزوهش تيمارهاى موردنظر

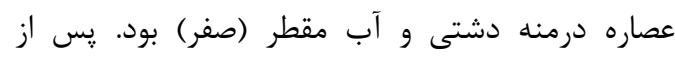
كشت، آبيارى هر بر ساعت يكبار انجام شد، تيمارها

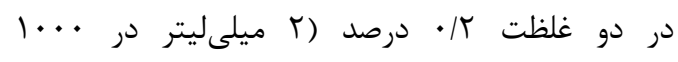

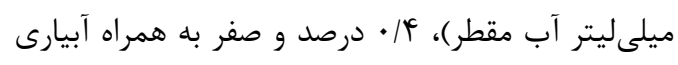

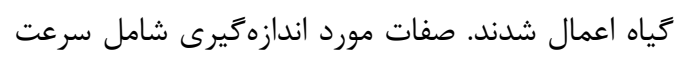
و درصد سبز شدن، طول ريشهجه، طول ساقهجه، وزن ترن

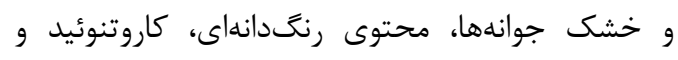
محتوى عناصر غذايى كهور ايرانى بود. اندازهَيرى صفات 
تيتراسيون، بلوسيله دستخاه كجلدال، فسفر با استفاده از روش رنخسنجى با استفاده از اسيكتروفتومتر و يتاسيهم

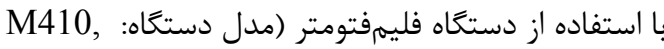
(Sherwood, London

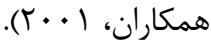

\section{تجزيه و تحليل دادهها}

گِ إز حصول اطمينان از نرمالبودن دادهها (آزمون

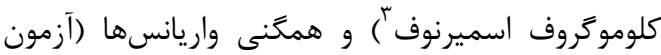

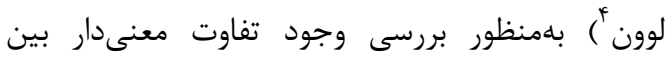
تيمارها، دادها مورد تجزيه واريانس يك بكرفه در در قالب طرح كاملاً تصادفى با جهار تكرار قرار گرفتند. تجزيه و تحليل دادهها، با نرمافزار 20 SPSS.

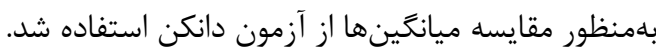

نتايج و بحث

\section{سرعت و درصد سبز شدن و خصوصيات رشد گياه}

نتايج مربوط به تأثير عصاره درمنه دشتى بر سرعت و درصد سبز شدن كهور ايرانى در جدول ا آورده شده

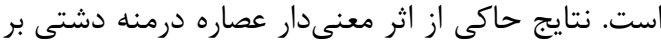

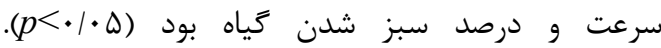
بهطورى كه در غلظت / / • درصد عصاره، بيشترين درصد و سرعت سبز شدن مشاهده شد.

كمترين سرعت و درصد سبز شدن مربوط به غلظت

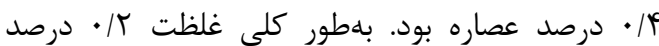
باعث افزايش سبز شدن بذر كهور ايرانى در مقايسه با

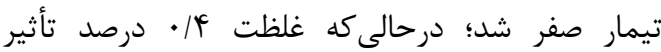
بازدارندگى بر سبز شدن بذرهاى گياه داشت.

مرحلهى سبزشدن زياه نسبت به ساير مراحل فنولوزيك از حساسيت بالايى برخوردار است. غلظت هايين عصاره بر سبز شدن اثر مثبت داشت. زيرا يديده دَرآسيبى به غلظت مواد شيميايى دَرآسيب بسيار وابسته است و ممكن است با تغيير در مقدار غلظت اين مواد اثر بازدارندكى و تحريك كنندگى متفاوتى بدست

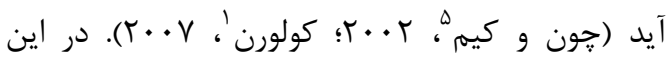

\footnotetext{
${ }^{2}$ Rayan

${ }^{3}$ Kolmogorov-Smironov

${ }^{4}$ Levene

${ }^{5}$ Chon and Kim
}

كلروفيل كل از مجموع كلروفيل a و b بر حسب ميلى -

كرم بر گرم وزنتر نمونه اندازهيرى شد (آرنون'

(1) 949

رابطه

Chlorophyll-a $=\left(19.3 \times \mathrm{A}_{663}-0.86 \times \mathrm{A}_{645}\right) \times$ V/1000w

رابطه

Chlorophyll-b $=\left(19.3 \times \mathrm{A}_{645}-3.6 \times \mathrm{A}_{663}\right) \times$ V/1000W

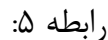

Carotenoid $=100 \times\left(\mathrm{A}_{470}\right)-3.27$ (chl.a) -104 $\times($ chl.b) / 227

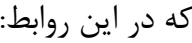

=V حجم محلول صاف شده (محلول فوقانى حاصل از سانتريفيوز)

FV. ج = A A و نانومتر = وزنتر نمونه برحسب گرم

\section{اندازهَيرى محتوى عناصر غذايى}

بهمنظور اندازهخيرى تأثير عصاره بر ميزان عناصر كياه، هضم نمونههاى گياهى از روش اكسايش تر انجام

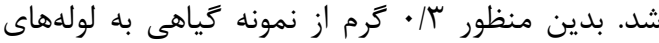
هضم منتقل و سيس / إ ميلىليتر از مخلوط اسيد سولفوريك، اسيد سالسيليك، سلنيوم و آب اكسيزنه به آنها اضافه شد. مخلوط حاصل تا دماى ...1 درجه سانتى گراد حرارت داده شد. بعد از خنك شدن نمونه آنها، يك ميلىليتر آب اكسيزنه (سه بار) به آنها اضافه شد.

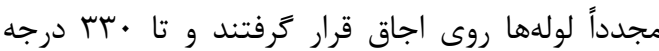
سانتى گراد حرارت داده شدند تا عمل هضم تمام شورى شود.

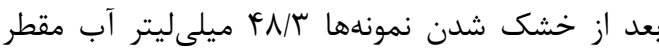
اضافه و همزده شدند. روز بعد عمل همزدن تكرار شد و بهحال خود قرار داده شد تا مواد تهنشين گردد.

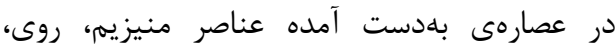
يتاسيم، فسفر و نيتروزن اندازهگيرى شدند. اندازهگيرى منيزيم و روى در عصاره حاصل از هضم تر نمونههاى

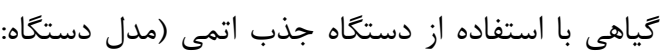
(Dena, Iran

\footnotetext{
${ }^{1}$ Arnon
} 
نشان داد با افزايش غلظت عصاره، طول ريشهجه و ساقه جه و همجنين وزن خشك گياه كاهش معنى

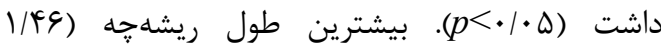

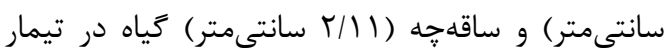
صفر اندازهىيرى شد و كمترين طول ريشه مربوط به تيمار غلظت ع/ • درصد بود (جدول (1).

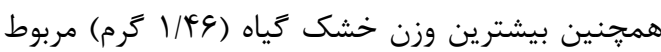

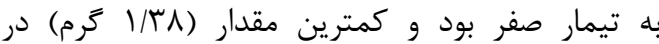
غلظت عصاره \&/ • درصد اندازهخيرى شد. اثرات دكرآسيبى در گونههاى مختلف جنس درمنس به اثبات رسيده است. در اين جنس طيف گستردهاى از

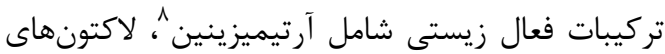

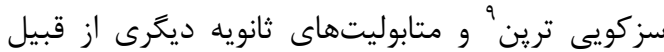

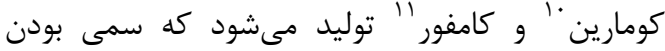

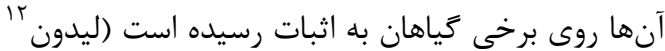

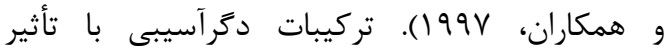
كذاشتن بر رشد ريشهها با كاستن از تشكيل ريشههاى مويينه باعث كاهش جذب آب در گياهان و درنتيجه

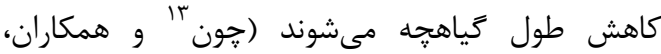

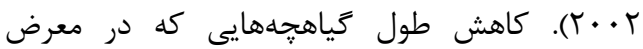
عصارههاى گياهى حاوى مواد بازدارنده قرار مى گيرند

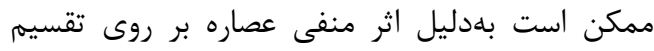

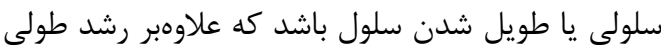
گياه، مواد بازدارنده موجود در عصاره گياهى مىتوانند

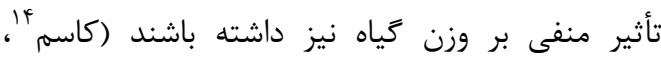

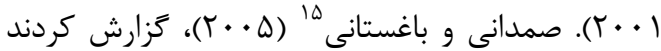
كه ميزان تأثير عصاره گونههاى مختلف درمنه روى

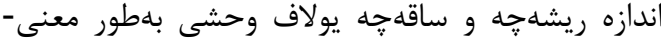

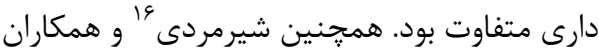

\footnotetext{
${ }^{8}$ Artemisinin

${ }^{9}$ Sesquiterpene lactone

${ }^{10}$ Coumarin

${ }^{11}$ Camphor

${ }^{12}$ Lydon

${ }^{13}$ Chon

${ }^{14}$ Qasem

${ }^{15}$ Samedani and Baghestani

${ }^{16}$ Shirmardi
}

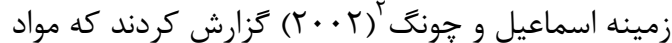
دكرآسيب در غلظتهاى يايين ممكن است اثرات مثبت يا منفى بر زياه هدف داشته باشند، اما در غلظتهاى بالا همواره بازدارنده باشند. علت كاهش درصد و و سرعت

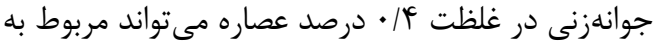

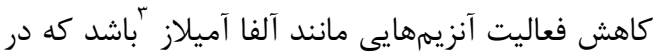
جوانهزنى بذر نقش مهمى دارد) باقرى و محمدى، $r \cdot \mid 1)$.

نتايج تحقيقات نشان داده است تركيبات دگرآسيب

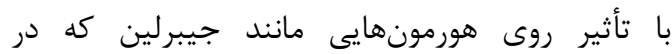
جوانهزنى مهرم هستند و همجنين با اثر روى فعاليت

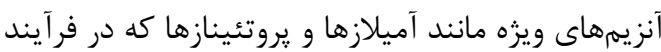
جوانهزنى ضرورى هستند، باعث كاهش جوانهزنى زياه مى گردند. علاوه بر اين توقف در مرحله سبز شدن ممكن است به تغيير فعاليت آنزيمهايى كه روى انتقال تركيبات ذخيرهاى در طى جوانهزنى اثر مى گذارد، نسبت دادئ

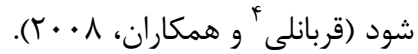

لازم به ذكر است كه مواد بازدارنده مترشحه از

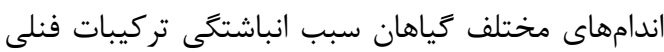
مىشود كه خود منجر به كاهش درصد جوانهزنى مجى

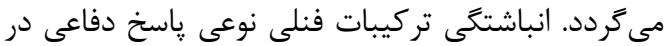
برابر تنشهاى زيستى و غيرزيستى است كه موجب

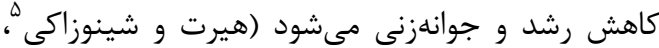

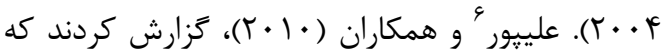
عصاره گَياه درمنه ظرفيت بازدارندگى جوانهزنى بذر و رشد گياهجه تاج خروس، سلمه تره، قياق ( Sorghum

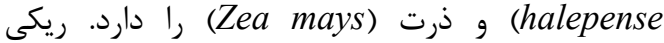

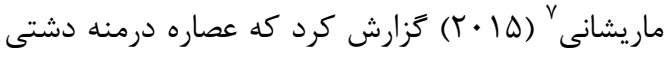

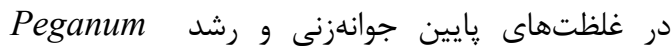
harmala باعث كاهش جوانهزنى و رشد گَياه گرديد. نتايج مربوط به تأثير عصاره درمنه دشتى بر رشد رسد كهور ايرانى در جدول ا نشان داده شده است. نتايج

\footnotetext{
${ }^{1}$ Koloren

${ }^{2}$ Ismail and Chong

${ }^{3} \alpha$-Amylase

${ }^{4}$ Ghorbanli

${ }^{5}$ Hirt and Shinozaki

${ }^{6}$ Alipoor

${ }^{7}$ Ricki Maryshany
} 
ريكى ماريشانى و همكاران: تأثير دكر آسيبى عصاره درمنه (Artemisia sieberi) بر خصوصيات سبز شدن...

جدول ا- مقايسه ميانكين اثر عصاره درمنه دشتى بر سبز شدن بذر و خصوصيات مورفولوزيك كهور ايرانى

Table 1. Mean comparison of the effect of A. sieberi extract on emergence and morphological properties of P. cineraria (L.) Druce

\begin{tabular}{|c|c|c|c|c|c|}
\hline $\begin{array}{c}\text { غلظت عصاره } \\
(\%) \\
\text { Extract } \\
\text { concentration (\%) }\end{array}$ & $\begin{array}{c}\text { سرعت سبز شدن بذر } \\
\text { (بر روز) } \\
\text { Seeds } \\
\text { emergence rate } \\
\left(\text { day }^{-1}\right) \\
\end{array}$ & $\begin{array}{c}\text { درصد سبز شدن بذر } \\
\text { Seeds emergence } \\
\text { percent }\end{array}$ & 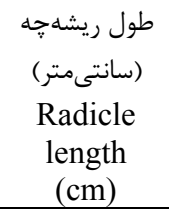 & 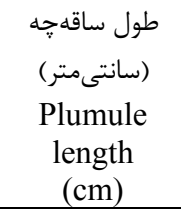 & 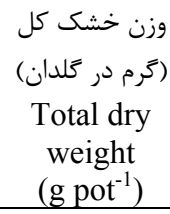 \\
\hline 0 & $7.00 \pm 0.40^{\mathrm{a}}$ & $33.30 \pm 2.40^{b}$ & $1.46 \pm 0.40^{\mathrm{a}}$ & $2.11 \pm 0.50^{\mathrm{a}}$ & $1.46 \pm 0.30^{\mathrm{a}}$ \\
\hline 0.2 & $7.43 \pm 0.40^{\mathrm{a}}$ & $41.60 \pm 2.60^{\mathrm{a}}$ & $1.42 \pm 0.40^{\mathrm{a}}$ & $1.38 \pm 0.30^{b}$ & $1.42 \pm 0.30^{\mathrm{a}}$ \\
\hline 0.4 & $6.75 \pm 0.42^{b}$ & $32.20 \pm 2.30^{b}$ & $1.38 \pm 0.30^{b}$ & $1.30 \pm 0.30^{b}$ & $1.38 \pm 0.20^{b}$ \\
\hline
\end{tabular}

در هر ستون، ميانگينهاى با حروف مشابه در سطح ه. آزمون دانكن با يكديخر اختلاف معنىدار ندارند.

In each column, means with similar superscript letters are not significantly different at $\mathrm{P}<0.05$ of Duncan's multi-range test.

كلروفيل b، كلروفيل كل و محتوى كاروتنوئيد بهدست

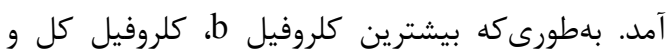
محتوى كاروتنوئيد مربوط به تيمار صفر بود و كمترين

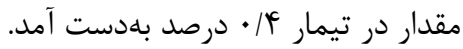
بيشتر تحقيقات مربوط به دگرآسيبى نشان دادر داده است كه كاهش رشد زياه در حضور مواد شيميايى دكرآسيب با كاهش كلروفيل در آنها همبستخى دارد و ممكن است كاهش كلروفيل يك اثر ثانويه ناشى از مهرمترين تركيبات فعال در زياه درمنه، آرتيميزينين باشد. اين ماده از طريق جلوگيرى از تقسيم و طويل شدن

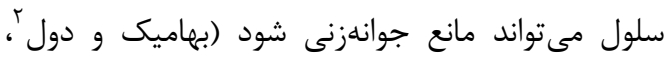

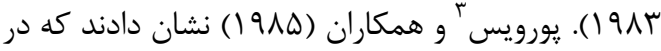
در اثر تجزيه و ترواش مواد از بقاياى جاودار در خاك،

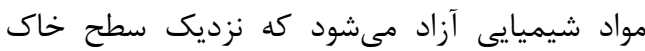
انباشته شده و از جوانهنى و رشد علفئهاى هرز جلوگيرى مىنمايد. اين مواد محلول در آب، بازدارنده

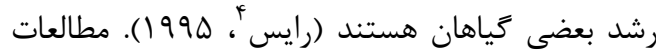
بسيارى نشان داده است كه بقاياى بعضى زياهان داراى

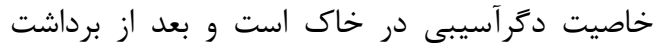
تركيباتى نظير اسيدهاى فنوليك آزاد مى كنند كه روى درى درى جوانهزنى بعضى كياهان يا عملكرد زياه اثر منفى دئى دارد

$$
\text { (هوفمن هو همكاران، (1999). }
$$

\footnotetext{
${ }^{2}$ Bhawmik and Doll

${ }^{3}$ Purvis

${ }^{4}$ Rice

${ }^{5}$ Hoffman
}

(Yו • (Y)، تأثير دگرآسيبى عصاره اندامهاى هوايى گونه A. aucheri Bذر Bromus tomentellus (علف يشمكى) و inermis

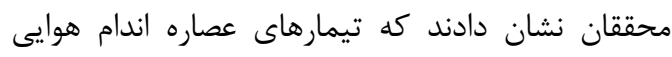
درمنه كوهى بر درصد و سرعت جوانهزنى، طول ريشهجه و ساقهجه و بنيه بذر دو گونه كاهش معنى دردارى داش داشت.

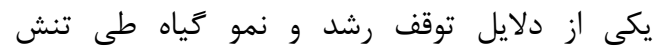
دَرآسيبى، تغيير نرخ تنفس ميتوكندريايى است كه باعث كاهش توليد ATP مىشود. كاهش توليد ATP مى تواند باعث تغيير در ساير فرآيندهاى سلولى مانند

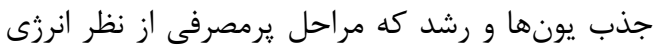
هستند، شود. كاهش رشد گياه در حضور تركيبات

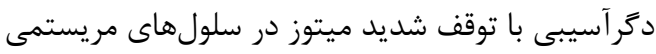

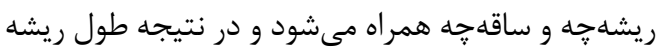

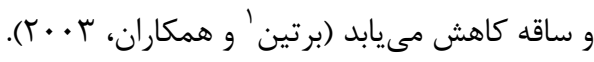

$$
\text { رنَيزههاى فتوسنتزى }
$$

نتايج مربوط به تأثير عصارههاى درمنه دشتى برى

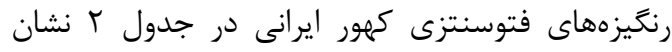
داده شده است. نتايج نشان داد عصاره درمنه دشتى باعث كاهش معنى دار رنخيزههاى فتوسنتزى كهور ايرانى

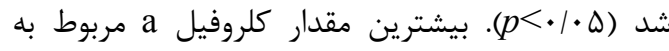
تيمار صفر بود و با افزايش غلظت عصاره درمنه دشتى

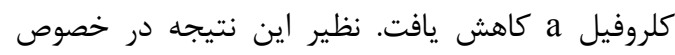

${ }^{1}$ Bertin 
جدول r- مقايسه ميانگين تأثير عصاره درمنه دشتى بر محتوى كلروفيل a، b، كلروفيل كل و كاروتنوئيد (ميلى

Table 2. Mean comparison of the effect of A. sieberi extract on chlorophyll a, b total chlorophyll and carotenoid content $\left(\mathrm{mg} \mathrm{g}_{\mathrm{Fw}}{ }^{-1}\right)$ of P.cineraria

\begin{tabular}{|c|c|c|c|c|}
\hline $\begin{array}{c}\text { غلظت عصاره (\%) }(\%) \\
\text { Extract concentration (\%) }\end{array}$ & $\begin{array}{c}a \text { كلروفيل } \\
\text { Chlorophyll } a\end{array}$ & $\begin{array}{c}b \text { كلروفيل } \\
\text { Chlorophyll } b\end{array}$ & $\begin{array}{c}\text { كلروفيل كل } \\
\text { Total Chlorophyll } \\
\end{array}$ & $\begin{array}{c}\text { كاروتنوئيد } \\
\text { Carotenoid } \\
\end{array}$ \\
\hline 0 & $1.680 \pm 0.010^{\mathrm{a}}$ & $0.796 \pm 0.065^{\mathrm{a}}$ & $2.477 \pm 0.221^{\mathrm{a}}$ & $1.17 \pm 0.01^{\mathrm{a}}$ \\
\hline 0.2 & $0.666 \pm 0.050^{b}$ & $0.729 \pm 0.065^{\mathrm{a}}$ & $1.396 \pm 0.143^{b}$ & $0.32 \pm 0.01^{\mathrm{b}}$ \\
\hline 0.4 & $0.517 \pm 0.055^{\mathrm{c}}$ & $0.607 \pm 0.052^{\mathrm{b}}$ & $1.125 \pm 0.135^{\mathrm{c}}$ & $0.03 \pm 0.00^{\mathrm{c}}$ \\
\hline
\end{tabular}

در هر ستون، ميانكَينهاى با حروف مشابه در سطح ه. آزمون دانكن با يكديكر اختلاف معنىدار ندارند.

In each column, means with similar superscript letters are not significantly different at $\mathrm{P}<0.05$ of Duncan's multi-range test.

اندازهخيرى شد و با افزايش غلظت عصاره مقدار يتاسيم

و منگنز كاهش يافت. در خصوص مقدار روى روند كاملاً متفاوتى مشاهده شد. بلهورى كه با افزايش غلظت عصاره درمنه دشتى مقدار روى در بافتهاى كياهى

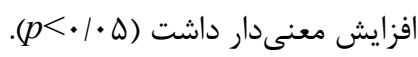
جذب عناصر غذايى براى رشد و توسعه گياه مهرم هستند. مطالعات نشان مىدهد كه تجمع بسيارى از عوامل دَرآسيبى روى سرعت جذب عناصر غذايى اثر مى گذارد. هردوى افزايش و كاهش در جذب مواد غذايى براى گياهانى ززارش شده است كه در معرض تعرى تغيير شرايط دَرآسيبى قرار دارند. وضعيت نامتعادل شدن مواد معدنى در گياهان گيرنده توسط آبشويى از بقاياى

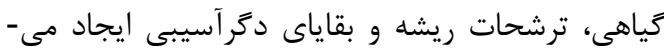

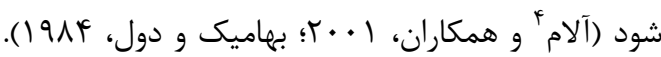
البته اين تأثيرات ممكن است مستقيماً مربوط به رقابت روابت كياهان باشد و ممكن است غيرمستقيم از طريق تأثير بر

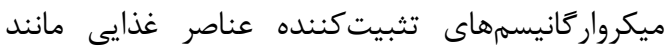
نيتروزن صورت گيرد. مواد شيميايى دَرآسيب خاص

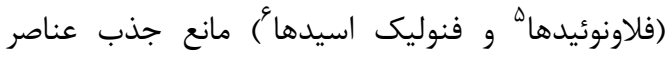
معدنى توسط ريشههاى گياه مىشوند و مكانيسم عمل اين تركيبات از طريق بهمزدن اعمال طبيعى غشاء در

$$
\text { سلولهاى كياه است. }
$$

نسيم' و همكاران (9 · · ؟) نشان دادند كه توليد مواد

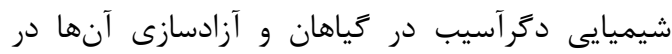
خاى توسط گياهان مىتواند جوانهزنى و رشد گونه

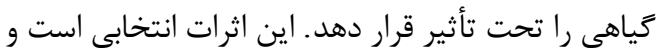

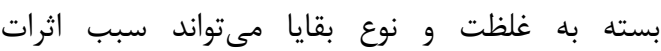
بازدارندگى يا تحريك كنندگى رشد در گياهان شود. مواد دَرآسيب مى توانند بر گياه مجاور ايجاد اختلال نمايند و مقدار كلروفيل كياه مجاور را تحت تأثير قرار دهند. علت كاهش ميزان كلروفيل در غلظتهاى بالا درنتيجه تجزيه رنخيزههاى كلروفيلى و كاروتنوئيدها و يا كاهش سنتز آنها است (تريياتى و كورى'، فرآيندهايى همانند تقسيم سلولى، توليد هورمونها، پايدارى و نفوذيذيرى غشاى سلولى، فتوسنتز و تنفس مى توانند بهعنوان هدف و نقطه اثر براى مواد دَّر آسيب

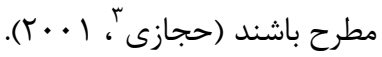

\section{محتوى عناصر غذايى} نتايج مربوط به تأثير عصاره درمنه دشتى بر محتوى عناصر غذايى كهور ايرانى در جدول ب آورده شده است. نتايج حاكى از اثر معنى دار عصاره درمنه دشتى بر ميزان نيتروزن، يتاسيه، فسفر، روى و منحَنز در بافتهاى كهور

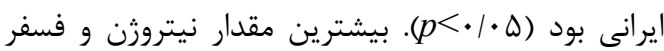
در تيمار ץ/ • درصد اندازهگيرى شد و كمترين مقدار نيتروزن و فسفر مربوط به تيمار \& א/ • درصد بود.

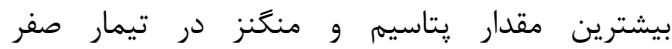

\footnotetext{
${ }^{1}$ Naseem

${ }^{2}$ Tripathi and Kori

${ }^{3}$ Hejazi
} 
ريكى ماريشانى و همكاران: تأثير دكر آسيبى عصاره درمنه (Artemisia sieberi) بر خصوصيات سبز شدن...

جدول r - ميزان عناصر غذايى موجود در بافتهاى كهور ايرانى تحت تأثير عصاره درمنه دشتى

Table 3. Nutrients contents in tissues of $P$. cineraria under $A$. sieberi extract

\begin{tabular}{|c|c|c|c|c|c|}
\hline $\begin{array}{c}\text { غلظت عصاره (\%) } \\
\text { Extract concentration (\%) }\end{array}$ & $\begin{array}{l}\text { نيتروزن (\%) } \\
\text { N (\%) }\end{array}$ & $\begin{array}{l}\text { شتاسيم (\%) } \\
\text { K (\%) }\end{array}$ & $\begin{array}{l}\text { فسفر (/) } \\
\text { P (\%) }\end{array}$ & $\begin{array}{l}\text { روى (.) } \\
\mathrm{Zn}(\%)\end{array}$ & $\begin{array}{l}\text { (/.) منزخن } \\
\text { Mn (\%) }\end{array}$ \\
\hline 0 & $2.85 \pm 0.20^{b}$ & $0.43 \pm 0.01^{\mathrm{a}}$ & $0.42 \pm 0.01^{b}$ & $0.13 \pm 0.00^{b}$ & $0.17 \pm 0.00^{\mathrm{a}}$ \\
\hline 0.2 & $3.03 \pm 0.33^{\mathrm{a}}$ & $0.41 \pm 0.01^{\mathrm{a}}$ & $0.53 \pm 0.01^{\mathrm{a}}$ & $0.15 \pm 0.00^{b}$ & $0.12 \pm 0.00^{b}$ \\
\hline 0.4 & $2.72 \pm 0.20^{b}$ & $0.34 \pm 0.01^{b}$ & $0.24 \pm 0.01 \mathrm{c}$ & $0.21 \pm 0.00^{\mathrm{a}}$ & $0.10 \pm 0.00^{b}$ \\
\hline
\end{tabular}

In each column, means with similar superscript letters are not significantly different at $\mathrm{P}<0.05$ of Duncan's multi-range test.

$$
\begin{aligned}
& \text { مثبت درمنه دشتى بر افزايش سبز شدن كهور ايرانى }
\end{aligned}
$$

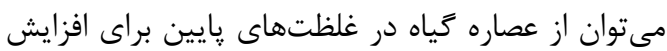

$$
\begin{aligned}
& \text { سبز شدن كهور ايرانى بلويزه در نهالستانها استفاده } \\
& \text { نمود. بالويزه اينكه كهور ايرانى داراى مشكل جوانهزنى }
\end{aligned}
$$

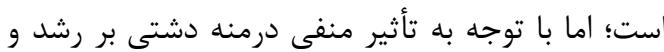

$$
\begin{aligned}
& \text { جذب عناصر غذايى در كهور ايرانى كشت اين دو زياه } \\
& \text { باهم در مراتع خشك توصيه نمىشود. }
\end{aligned}
$$

مواد شيميايى دخرآسيب مىتوانند از طريق ممانعت

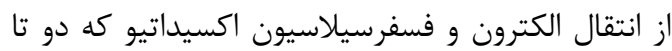
از اعمال غشاء ميتوكندريايى هستند، محتوى ATP سلول را كاهش دهند و همجنين ميىتوانند خاصيت نفوذيذيرى غشاء را نسبت به جذب يونهاى معدنى

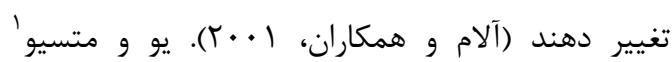
Cucumis sativus اثرات ترشحات ريشه (199V) (خيار)، اسيدهاى كربوكسيليك آروماتيك در ترشحات

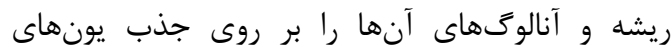

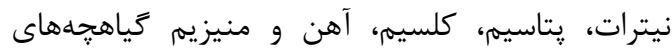
خيار بررسى كردند. نتايج آنها نشان داد كه ترشحات ريشه مانع جذب تمام يونهاى نامبرده شد.

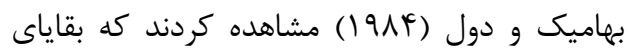
Ambrosia دم روباهى زرد) Setaria glauca I artemisifolia

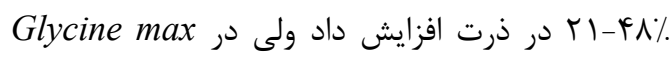

$$
\text { (سويا) جنين نبود. (س) }
$$

$$
\text { نتيجه گيرى }
$$

نتايج مطالعه حاضر نشان مىدهد با افزايش غلظت عصاره درمنه دشتى، صفات مورفولوزيك و رنخيزههاى فتوسنتزى كهور ايرانى كاهش مىيابند. عصاره درمنه بر جذب عناصر غذايى توسط كهور ايرانى تأثير متفاوت داشت. بلهورى كه در غلظتهاى پايين باعث افزايش جذب نيتروزن و فسفر و در غلظتهاى بالا باعث افزايش جذب منگنز مى گردد. غلظت / / • درصد عصاره درمنه روى سبز شدن گياه تأثير مثبت دارد. با توجه به تأثير

\footnotetext{
${ }^{1} \mathrm{Yu}$ and Matsui
} 
Alam, S.M., Ala, S.A., Azmi, A.R., Khan, M.A., and Ansari, R. 2001. Allelopathy and its role in agriculture. Journal of Biological Science, 1: 308-315. https://doi.org/10.3923/jbs.2001.308.315

Alipoor, Sh., Filizadeh, Y., and Montazeri, M. 2010. Evaluation allelopathic effects of Artemisia annua L. on weed plant (Zea mays). Weed Research Journal, 2(1): 69-83. [In Persian with English Summary].

Al-Rowaily, S.L., El-Bana, M.I., Al-Bakre, D.A., Assaeed, A.M., Hegazy, A.K., and Ali, M.B. 2015. Effects of open grazing and livestock exclusion on floristic composition and diversity in natural ecosystem of Western Saudi Arabia. Saudi Journal of Biological Sciences, 22(4): 430437. https://doi.org/10.1016/j.sjbs.2015.04.012

Arnon, D.I. 1949. Copper enzymes in isolated chloroplasts. Polyphenol oxidase in Beta vulgaris plant. Plant Physiology, 24(1): 1-5. https://doi.org/10.1104/pp.24.1.1

Bagheri, R., and Mohammadi, S. 2011. Allelopathic effects of Artemisia sieberi Besser on three important species (Agropyron desertorum, Agropyron elongatum and Atriplex canescens) in range improvement. Iranian Journal of Range and Desert Research, 17: 538-549. [In Persian with English Summary].

Bajji, M., Kinet, J.M., and Lutts, S. 2002.Osmotic and ionic effects of $\mathrm{NaCl}$ on germination, early seedling growth, and ion content of Atriplex halimus (Chenopodiaceae). Canadian Journal of Botany, 80(3): 297-304. https://doi.org/10.1139/b02-008

Bertin, C., Yang, X., and Weston, L.A. 2003. The role of root exudates and allelochemicals in the rhizosphere. Plant and Soil, 256(1): 67-83. https://doi.org/10.1023/A:1026290508166

Bhawmik, P.C., and Doll, J.D. 1983. Growth analysis of corn and soybean response to allelopathic effects of weed residues at various temperatures and photosynthetic photon flux densities. Journal of Chemical Ecology, 9(8): 1263-1280. https://doi.org/10.1007/BF00982228

Bouchikh-Boucif, Y., Labani, A., Bebabdeli, K.H., and Bouhelouane, S. 2014. Allelopathic effects of shoot and root extracts from three alien and native Chenopodiaceae species on lettuce seed germination. Ecologia Balakanica, 6(2): 51-55.

Chillo, V., Ojeda, R.A., Anand, M., and Reynolds, J.F. 2015. A novel approach to assess livestock management effects on biodiversity of dry lands. Ecological Indicators, 50: 69-78. https://doi.org/10.1016/i.ecolind.2014.10.009

Chon, S.U., and Kim, J.D. 2002. Biological activity and quantification of suspected allelochemicals from Alfalfa plant parts. Journal of Agronomy and Crop Science, 188(4): 281285. https://doi.org/10.1046/j.1439-037X.2002.00574.X

Chon, S.U., Choi, S.K., Jang, H.G., Pyo, B.S., and Kim, S.M. 2002. Effects of alfalfa leaf extracts and phenolic allelochemicals on early seedling growth and root morphology of alfalfa and barnyard grass. Crop Protection, 21: 1077-1082. https://doi.org/10.1016/S0261-2194(02)00092$\underline{3}$

Ghaderi Vangah, B., Safaeeian, N., and Sadeghi, S.H.R. 2008. The effect of alfalfa (Medicago sativa) sowing on some vegetation characteristics of natural rangelands. Pajouhesh and Sazandegi, 79: 166-172. [In Persian with English Summary].

Gholami, P., Ghorbani, J., and Ghaderi, Sh. 2011. Allelopathic effects of Artemisia aucheri on seed germination and Dactylis glomerata properties of Festuca arundinacea Schreb. Plant Ecophysiology, 9: 41-52. [In Persian with English Summary].

Ghorbanli, M.L., Bakhshi Khanegi, G.R., and Shojaie, A.A. 2008. Survey of allelopathic potential of Artemisia siberi Beeser on Avena lodoviciana seedling and Amaranthus retroflexus. Pajouhesh and Sazandegi, 129-134. [In Persian with English Summary]. 


\section{ريكى ماريشانى و همكاران: تأثير دكر آسيبى عصاره درمنه (Artemisia sieberi) بر خصوصيات سبز شدن...}

Hejazi, A. 2001. Allelopathy (Autotoxicity and Hetrotoxicity. University of Tehran press, 181 p. [In Persian].

Hoffman, M.L., Weston, L.A., Shyder, J.C., and Regnier, E.E. 1996. Separating the effects of sorghum (Sorghum bicolar) and rye (Secale cereal) root and shoot residues on weed development. Weed Science, 44: 402-407.

Iman, A., and Zakaria, W. 2006. Allelopathic effect of sweet corn and vegetable soybean extracts at germination and seedling growth of corn and soybean varieties. Journal of Agronomy, 25: 6268 .

Ismail, B.S., and Chong, T.V. 2002. Effect of aqueous extract and decomposition of Mikania micrantha on selected agronomic crops. Weed Biology Management Journal, 2: 31-38. https://doi.org/10.1046/j.1445-6664.2002.00045.x

Jangali, K., Salehi, P., and Jafari, A. 2012. The investigation of the genetic variability for yield and morphological and seedling characteristics in of Bromegrass populations. Plant and Ecosystem, 8(1): 14-29. [In Persian with English Summary].

Kazerooni Monfared, S., Tokasi, M., and Banayan Awal, M. 2013. Study of allelopathic effects of berseem clover (Trifolium alexandrium) shoot aqueous extract on germination and initial seedling growth of some weed species. Journal of Plant Protection. 27: 509-512. [In Persian with English Summary].

Koloren, Q. 2007. Allelopathic effects of Medicago sativa L. and Vicia cracca L. leaf and root extracts on weeds. Pakistan Journal of Biological Science, 10(10): 1639-1642. https://doi.org/10.3923/pjbs.2007.1639.1642

Lydon, J., Rteasdele, J., and Chen, P.K. 1997. Allelopathic activity of annual wormwood (Artemisia annua) and the role artemisinin. Weed Science, 45: 807-811.

Narwal, S. 2004. Allelopathy in crop production. Jodhpur, Scientific Publishers. 303 p.

Naseem, M., Aslam, M., Asnar, M., and Azhar, M. 2009. Allelopathic effects of sunflower water extract on weed control and wheat productivity. Pakistan Journal of Weed Science Research, 15: 107-116.

Purvis, C.E., Jessop, R.S., and Lovea, J.V. 1985. Selective regulation of germination and growth of annual weeds by crop residues. Weed Research, 25(6): 415-421. https://doi.org/10.1111/j.1365-3180.1985.tb00664.x

Qasem, J.R. 2001. Allelopathic potential of white top and Syrian sage on vegetable crops. Journal of Agronomy, 93: 64-71. https://doi.org/10.2134/agronj2001.93164x

Rice, E.L. 1995. Biological control of weeds and plant diseases. University of Oklahoma press, Norman and London. 439 p.

Ricki Maryshany, A. 2015. Effects of Trifolium alexandrium, Artemisia sieberi and fertilizer on agree extract on germination and morphological properties of Peganum harmala and Prosopis cineraria. Range Management M.Sc. Thesis. University of Zabol, 86 P. [In Persian with English Summary].

Ryan, J., Estefan, G., and Rashid, A. 2001. Soil and plant analysis laboratory manual, international centre for agricultural research in the dry areas (ICARDA). Aleppo and National Agricultural Research Centre (NARC), Islamabad, Pakistan. 172 p.

Samedani, B., and Baghestani, M.A. 2005. Comparison of allelopathic activity of different Artemisia species on seed germination rate and seedling growth of Avena ludoviciana. Pajouhesh and Sazandegi, 68: 69-74. [In Persian with English Summary].

Shirmardi, H.A., Ghaderi, Sh., Gholami, P., and Amozegar, L. 2013.The allelopathic effect of Artemisia aucheri Boiss on some seed germination properties of Bromus tomentellus Boiss and 
Bromus inermis Leyss. Journal of Plant and Ecosystem Conservation, 1(2): 71-80. [In Persian with English Summary].

Tripathi, S.A., and Kori, D.C. 1999. Allelopathic evolution of Tectona grandis leaf, root and soil aqua extracts on soybean. Indian Journal of Forestry, 22: 366-374.

Yu, Q.J., and Matsui, Y. 1997. Effect of root exudates of cucumber (Cucumis sativus) and allelochemicales on ion uptake by cucumber seedlings. Journal of Chemical Ecology, 23: 817827. https://doi.org/10.1023/B:JOEC.0000006413.98507.55 


\title{
Effect of Artemisia sieberi Extract Allelopathy on Emergence Characteristics and Nutrients Uptake of Prosopis cineraria
}

\author{
Asma Ricki Maryshany ${ }^{1}$, Mahdieh Ebrahimi ${ }^{2,}$ ", Ebrahim Shirmohammadi ${ }^{3}$
}

\section{Extended abstract}

Introduction: Allelopathic effects of plant on one another are one of the most important concerns in reclamation and rehabilitation of rangelands in Iran. Allelopathy refers to the deterrent effects of a plant on growth, development or emergence of another plant. One of the rangeland reclamation methods is planting suitable and compatible species. However, without considering the plant's allelopathis characteristic, it is highly likely that the project will be a failure. The present study sought to investigate the effects of Artemisia sieberi extract on seedling emergence, some morphological characteristics and nutrient uptake of Prosopis cineraria which has hard emergence.

Materials and Methods: The present study was carried out under greenhouse conditions, with $23 \pm 5{ }^{\circ} \mathrm{C}$, $60 \%$ relative humidity and $70 \%$ water-holding capacity of soil. The experimental design was a completely randomized one with four replications. Soil samples were selected from Deging village, located in the city of Khash (Sistan and Baloochestan Province). In order to prepare the plant extract, the $A$. sieberi samples were dried in the shade and were ground to powder. Then, $190 \mathrm{~g}$ of the powder was put in a plastic bottle, then filled with $1 \mathrm{~L}$ ethanol and placed on a shaker for 24 hours. The resulting solution was filtered out and the extract was obtained. The planting was carried out in plastic pots with the capacity of $6 \mathrm{~kg}$ which were filled with $3 \mathrm{~kg}$ of soil. In each pot, 30 seeds were buried, at a depth of $3 \mathrm{~cm}$. The treatments were treated at concentrations of $0.2 \%$ ( $2 \mathrm{ml}$ in $1000 \mathrm{ml}$ distilled water), $0.4 \%$, and zero along with plant irrigation. The parameters measured included emergence percentage and rate, radicle and pedicel length, seedling dry weight, photosynthetic pigments, carotenoid contents and nutrient uptake of $P$. cineraria.

Results: The results showed that $A$. sieberi extract significantly decreased plant photosynthetic pigments. The highest chlorophyll $\mathrm{a}, \mathrm{b}$, total chlorophyll and carotenoid belonged to the control treatment and by increasing extract concentration, photosynthetic pigments decreased. In addition, the findings were that the highest and lowest nitrogen and phosphorus contents were obtained in the 0.2 and $0.4 \%$ treatments, respectively. Potassium and manganese decreased with increases in extract concentration. However, with increases in extract concentration, zinc significantly increased in the plant tissues. In general, the results showed that $A$. sieberi extract increases $P$. cineraria emergence in the $0.2 \%$ treatment.

Conclusion: In general, morphological traits and photosynthetic pigments of $P$. cineraria decreased with increases in the concentrations of $A$. sieberi extract. Artemisia extract had a different effect on the absorption of nutrients by $P$. cineraria. at low concentrations. It increased nitrogen and phosphorus adsorption and increased concentrations of manganese in high concentrations. The concentration of $0.2 \%$ of Artemisia extract had a positive effect on plant emergence. Given the positive effect of $A$. sieberi on the emergence of $P$. cineraria, plant extract at low concentrations can be used to increase emergence of $P$. cineraria, especially given that the $P$. cineraria has an emergence problem. However, due to the negative effect of $A$. sieberi on growth and absorption of nutrients in $P$. cineraria, the cultivation of these two plants is not recommended in dry rangelands.

\section{Keywords: Allelopathy, Emergence percentage, Manganese, Photosynthetic pigments}

\section{Highlights:}

1- The extract of $A$. sieberi had deterrent effects on seed emergence and morphological characteristics of $P$. cineraria.

2- Increasing the concentration of the A. sieberi extract led to a decrease in the morphological characteristics of $P$. cineraria.

3- A. sieberi extract had negative effects on photosynthesis pigments of $P$. cineraria.

\footnotetext{
${ }^{1}$ Graduated M.Sc. Student of Range Management, Department of Range and

Watershed Management, University of Zabol, Zabol, Iran.

${ }^{2}$ Associate Professor, Department of Range and Watershed Management, University of Zabol, Zabol, Iran.

${ }^{3}$ Instructor, Department of Soil Engineering, Soil and Water Engineering Faculty, University of Zabol, Zabol, Iran.
}

*Corresponding author, E-mail address: maebrahimi2007@uoz.ac.ir

DOI: 10.29252/yujs.5.1.21

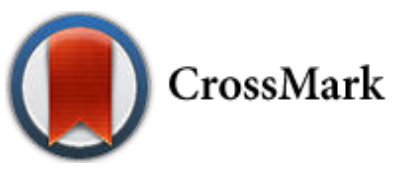

